\title{
Influence OF SCHOOL SCHEdULES ON PHYSICAL Activity Patterns in Primary Schoolchildren: A CASE STUdY IN ITALY
}

\section{Running head: School schedule and Physical Activity in children}

Revised version of the manuscript JPAH.2016-0492 R3 on January 31, 2017

\section{BRIEF REPORT}

Keywords: accelerometry, sedentary behavior, behavioral science

This manuscript is composed by 2246 words.

The abstract is 200 words long 


\section{$1 \quad$ Abstract}

3 Background: Considering the relevant amount of time spent by children at school, it is 4 essential to ensure that suitable levels of physical activity (PA) are guaranteed. This study 5 aimed to assess possible changes induced in the amount and type of PA performed following 6 the two schedules in Italian primary schools, namely regular and full time $(30-40 \mathrm{~h} / \mathrm{week}$ 7 respectively).

8 Methods: A sample of 169 children wore a tri-axial accelerometer $24 \mathrm{~h} /$ day for 7 consecutive 9 days. Raw data were processed to calculate the number of steps, amount and intensity of the 10 PA performed in morning, afternoon and evening time slots.

11 Results: During weekday afternoon times (1:30 - 4:30 PM), children attending the full-time 12 schedule spent significantly less time in sedentary behavior with respect to those who attend 13 the regular time $(54.7 \%$ vs. $60.0 \%, \mathrm{p}<0.001)$ and more time in moderate-to-vigorous activity $14(18.0 \%$ vs. $15.0 \%, p=0.004)$. No differences between morning and evening times were found.

15 Conclusions: The structure of the full time schedule, which includes a second recess, promotes

16 higher and more intense levels of PA during the afternoon. Such information represent a useful 17 input in planning differential PA activities for children attending the regular time to achieve similar PA levels for the whole school population. 
The analysis of primary school time organization in European countries reveals the existence of a wide variety in the number of daily and yearly lesson hours. Although the prevalent schedule is based on 4-5 daily hours 5-6 days/week, ${ }^{1-2}$ the timetable can be arranged in either one or two lesson periods that may take place in the morning only or in both morning and afternoon. In the latter case, the two lesson periods are interspersed by a midday break for lunch, which can be taken at home or directly at school. In some countries, afternoon time slots are reserved for extra-curricular activities only.

In this context, the situation in Italy is quite peculiar because, at the time of enrollment, parents are free to choose between two schedules, i.e. "regular time" (30 h/week Monday to Saturday, 8:30 AM to 1:30 PM) and "full time" (40 h/week Monday to Friday, 8:30 AM to 4:30 PM). The latter option was introduced in 1971 basically to meet two specific needs of families, namely the impossibility of parents to leave their workplace at midday to take children from school and the difficulties (especially in the case of low-education family environments) in properly supporting children during homework tasks. Since its introduction, the full time schedule has gained increasing popularity so that currently approximately one third of the primary school population opts for this kind of schedule. ${ }^{3}$ In northern and central regions of the country, children attending the full time schedule are the majority.

Although there are no differences in terms of time dedicated to frontal lessons (which amounts for all children to $27 \mathrm{~h} /$ week not considering the recesses), after 1:30 PM children who attend the full time schedule follow a fixed timetable that includes lunch (1h), a second recess (1h) and 2 additional hours of afternoon lessons, while regular time leaves families free to organize their children's activities. It is unknown to what extent these differences impact physical activity (PA) patterns, as structured activities (e.g. attending a sport training session) typically start in early afternoon. Thus the full-time school schedule may represent a sort of barrier against participation in PA or, at very least, a reduction of the allowable time slot for this purpose. Unfortunately, no specific studies have thus far targeted this issue. 
Objective quantitative measurement and classification of both amount and intensity of

PA in primary schoolchildren are often performed using wearable miniaturized accelerometers, ${ }^{4}$ which are currently available at an affordable price and allow continuous data acquisition up to several weeks. A number of studies have been carried out with this technique to assess the extent of sedentary behavior, ${ }^{5-7}$ which is closely related to obesity, to investigate the effects of specific changes in PA levels, ${ }^{8}$ to analyze the influence of the school setting and environmental factors ${ }^{9-11}$ and verify the differences in PA patterns referring to lessons/recess and in/out school time. ${ }^{12-16}$

This approach appeared suitable for this study, whose main purpose was to quantify PA levels in a sample of primary schoolchildren to clarify whether a different school-schedule could originate different patterns of PA during different periods of the day while keeping unchanged the other external variables associated with the school environment. Our hypothesis was that while the morning time is characterized by the same activities for all children, and thus no differences in PA levels would be expected, some alterations would be evident in the afternoon-evening periods.

Methods

Participants

The study was performed from November 2015 to February 2016 in an inner city public primary school located in Cagliari (Sardinia, Italy 154,478 inhabitants). Initially, the whole school population (473 families of $1^{\text {st }}$ to $5^{\text {th }}$ grade children) was informed about the purposes of the study through dedicated meetings and flyers. Of these, $202(43 \%)$ expressed interest in participating and signed an informed consent form after a detailed explanation of the methodology to be used. The study was carried out in compliance with the ethical principles 
73 for research involving human subjects expressed in the Declaration of Helsinki, and was

1
approved by the local ethics committee (authorization no. PG/2015/16965).

As the primary goal of the study was the objective quantification and classification of PA, the main exclusion criterion was the existence of severe musculoskeletal or neurological diseases that could impair everyday activities (in particular walking). However, none of the potentially interested children was affected by such conditions, as reported by their parents. Participants were enrolled in both school schedules, namely regular and full time. Table 1 shows the detailed schedules of the two options”

\section{Please insert Table 1 approximately here}

\section{Data collection and processing}

A tri-axial accelerometer (Actigraph GT3X, Acticorp Co., Pensacola, USA) was employed to collect data on PA. Each child was supplied with a unit on a Monday morning and asked to wear the device on the dominant wrist for 7 consecutive days $24 \mathrm{~h} /$ day, instructing him/her to remove it only for showering, water-based sports (i.e. swimming, water polo etc.) and contact sports in all cases in which the accelerometer might possibly cause injury to the child or the performed activity might damage the device. The choice of the wrist as the site of placement was made to increase wear time compliance and provide data on sleep. ${ }^{17-18}$ Having 20 devices available, each week we randomly selected 10 children attending regular time and 10 attending full time schedules.

The accelerometers were set to collect data using 10-s epochs and $30 \mathrm{~Hz}$ frequency. At the end of the measurement period, raw data were processed using ActiLife software v6.13.2 to perform step counts and PA classification on the basis of the cut-points defined by Crouter, Flynn $\&$ Bassett $^{17}$ for the acceleration vector magnitude (VM) defined as follows: 


$$
V M=\sqrt{x^{2}+y^{2}+z^{2}}
$$

where $\mathrm{x}, \mathrm{y}$ and $\mathrm{z}$ are the accelerations recorded by the device in each of the three directions. In

100 particular, we used the VM regressive model that classifies PA as follows: sedentary (SB, VM

$101 \leq 100)$, light (LPA, VM = 101-609), moderate (MPA, VM = 610-1809) and vigorous (VPA,

102 VM>1809). Moderate-to-vigorous PA (MVPA) was calculated by summing MPA and VPA.

103 The weekday percentage of time spent on each PA category and the number of steps were 104 calculated for morning (8:30 AM - 1:30 PM), afternoon (1:30 - 4:30 PM) and evening (4:30 105 10:30 PM) time slots. During the morning, students attending both types of schedule perform 106 the same activities, while only full time students are at school in the afternoon slot.

107 Anthropometric data necessary to initialize the device (i.e. stature and body mass) were 108 recorded using an ultrasonic digital height meter (Soehnle 5003, Soehnle Germany) and a 109 digital scale (RE310, Wunder, Italy). The Body Mass Index (BMI = weight/stature $\left.{ }^{2}\right)$ was 110 calculated and children were classified as normal weight, overweight or obese according to the 111 cut-off points defined by Cole et al. ${ }^{19}$

112 If daily wear time exceeded $16 \mathrm{~h} /$ day for the entire week of the test, the acquired data

113 were deemed valid, and the child participated in the subsequent analysis. Non-wear time was

114 defined as a time interval of at least 60 consecutive minutes of zero counts.

Statistical Analyses

117 The differences in PA induced by the school schedule were assessed using one-way 118 multivariate analyses of variance (MANOVA) performed using SPSS software (v.20, IBM, 119 Armonk, NY, USA). The independent variable was schedule (regular/full time) while the 4 120 dependent variables were the number of steps and the percentage of time spent in SB, LPA and 121 MVPA. 

squared coefficient $\left(\eta^{2}\right)$. Follow-up analyses were conducted using one-way ANOVAs for each

124 dependent variable by setting the level of significance at $p=0.0125(0.05 / 4)$ after a Bonferroni adjustment for multiple comparisons. The analysis was performed for each time slot.

\section{Results}

Of the 202 children wearing the accelerometer, 33 (16.3\%) did not meet the required wear-time criterion and were excluded from the analysis. In most cases, non-compliant participants reported that they were sick or forgot to wear the device after personal hygiene or a training session and then put it on again after a few days. Thus, the subsequent analysis refers to 169 children (76 boys, 93 girls, age $8.6 \pm 1.5$ ) all Caucasian. Their main anthropometric features and device wear times are shown in Table 2. The sample included 16 overweight and obese children ( 7 boys, 9 girls, $9.5 \%$ of the whole sample). The whole study took approximately 11 weeks to be completed. revealed a significant effect of school schedule for the afternoon $\left[F_{(4,164)}=2.74, p=0.03\right.$, Wilks $\left.\lambda=0.94, \eta^{2}=0.06\right]$ and morning $\left[F_{(4,164)}=4.99, p=0.001\right.$, Wilks $\left.\lambda=0.89, \eta^{2}=0.11\right]$ but not

143 the evening $\left[F_{(4,164)}=1.17, p=0.33\right.$, Wilks $\left.\lambda=0.97, \eta^{2}=0.03\right]$. 
Follow-up ANOVA carried out for the afternoon slot showed that significant differences involved the time spent in SB, which was less in the full-time students $(54.7 \%$ vs. $60.1, \mathrm{p}<0.001)$, while they were characterized by a higher percentage of MVPA $(18.0 \%$ vs. $14.9 \%, \mathrm{p}=0.004)$. For the morning slot, ANOVA revealed that no parameter reached statistical significance after the Bonferroni correction.

\section{Discussion and conclusions}

Examining the overall PA patterns in the accelerometric data, one notes that the number of daily steps $(\sim 12600)$ and the average time spent in SB by the children tested calculated on the whole day basis $(\sim 63 \%)$ agree well with those of similar studies. ${ }^{5-7,20}$ Interestingly, the percentage of MVPA in our sample $(\sim 14 \%)$ is higher than the average values by $6-8 \%$ reported in large European and American epidemiologic studies. ${ }^{5,6,20,21}$ Two possible reasons for such differences are the limited presence in our cohort of overweight/obese children, who are usually characterized by the lowest percentage of $\mathrm{MVPA}^{22}$ and favorable environmental conditions (Cagliari has a mild climate throughout the year) that allow recess mostly outdoors, so children can participate in more intense activities. ${ }^{11}$ schedule is partly confirmed by our data: full-time schoolchildren spend significantly less time in SB and more time in MVPA in the afternoon. This can be associated with differences in the way the post-lunch time is arranged by families compared to the structured activity organized by the school. The presence of a second $1 \mathrm{~h}$ long recess is likely to result in more intense PA levels for children still at school, in agreement with previous studies, in which recess time was found to be one of the main contributors to overall MVPA. ${ }^{12-14}$ In contrast, regular time

171 schoolchildren appear to use this time basically to do their homework or relax, play videogames

172 or watch TV. This results in larger proportions of SB, thus making after-school time (or out- 
173 of-school time in general) the most critical periods in which interventions targeted to increase

174 PA levels should be directed. ${ }^{16,23}$

175 Some limitations of the study are to be acknowledged: firstly, as previously mentioned,

176 the tested sample included a suspiciously limited number of overweight/obese children. In fact,

177 a previous study, recently performed by the authors on a larger sample of children of the same

178 school, showed that the percentage of overweight/obese individuals was $30 \%,{ }^{24}$ a value much

179 higher than the $9.5 \%$ that was observed in the present investigation. We hypothesize that

180 overweight children (and possibly their families) might have been somewhat reluctant to be

181 evaluated, as their condition embarrasses them, similarly to what was observed in previous

182 studies as regards anthropometric measurements. ${ }^{25}$ Secondly, as only 20 devices were

183 available, it was impossible to test all the participants in the same week. Although we took care

184 to deliver the accelerometers to an equal number of full and regular time children each week

185 (i.e. 10 of full time and 10 of regular time), changes in environmental conditions while passing

186 from autumn to winter may have influenced the results, at least in absolute terms. Moreover,

187 the fact that water and accidental impacts may damage the accelerometer certainly influenced

188 the quality of collected data, as children engaged in swimming, waterpolo and contact sports

189 were asked to remove the device during their training. This likely resulted in underestimation

190 of their PA levels. However, considering the fast advancements in the technology of wearable

191 activity trackers, we think that it will soon become possible to overcome some of these

192 limitations. At last, unfortunately we did not have access to socio-economic status data of the

193 families of the tested children, and this factor is known to have a relevant influence on PA

194 levels, as demonstrated in previous studies. ${ }^{26-27}$ For all these reasons, and also considering that

195 the sample here tested refer to an inner city residential area, our results may not be generalizable

196 to different geographic and socio-economic contexts, such as rural areas. Future studies should

197 investigate the effects of such variables (i.e. obese/overweight, low/high income, urban/rural

198 area) on the overall PA levels for children who attend different school schedules, and also 
199 verify the propensity of the schools in encouraging them to be engaged in PA activities during 200 recesses.

201 In conclusion, the results presented here highlight the role of the school schedule as an 202 important determinant of PA levels in primary schoolchildren, especially in terms of time spent 203 in SB and MVPA. While in the specific case of the Italian school system the imbalances 204 observed between full-time and regular-time children could be corrected with proper measures, 205 which should include a suitable afternoon PA program dedicated to regular-time students, it is 206 reasonable to hypothesize that other kinds of flexible schedules existing in other countries may 207 create similar phenomena.

208

209 Acknowledgments

210 The authors would like to thank the children who participated in the research, their parents and 211 teaching staff.

\section{Funding}

214 This study was funded by the University of Cagliari 


\section{References}

1. Kamette F. Organisation of school time in the European Union. Foundation Robert Schuman. 2011; Accessed August 8th, 2016 from http://www.robertschuman.eu/en/doc/questions-d-europe/qe-212-en.pdf.

2. Symonds JE, Hagell A. Adolescents and the organization of their school time: a review of changes over recent decades in England. Educ Rev. 2011; 63(3): 291-312.

3. Italian Ministry of Education, Universities and Research (MIUR) Statistical Service.

Focus. Le iscrizioni al primo anno delle scuole primarie, secondarie di primo e secondo grado del sistema educativo di istruzione e formazione (Report on the enrolments in the first year of primary and secondary schools in the Italian Education System, in Italian). 2015. Accessed August 8th, 2016 from http://www.istruzione.it/allegati/2015/Focus_iscrizioni_as2015_2016_pubblicazione. pdf.

4. Hills PH, Mokhtar N, Byme NM. Assessment of physical activity and energy expenditure: an overview of objective measures. Front Nutr. 2014; 1-5. doi: 10.3389/fnut.2014.00005.

5. Konstabel K, Veidebaum T, Verbestel V, Moreno LA, Bammann K, Tornaritis M et al. Objectively measured physical activity in European children: the IDEFICS study. Int J Obes. 2014; 38: S135-S143.

6. van Stralen MM, Yildirim M, Wulp A, te Velde SJ, Verloigne M, Doessegger A et al. Measured sedentary time and physical activity during the school day of European 10to 12-year-old children: the ENERGY project. J Sci Med Sport. 2014; 17: 201-206. 
7. Aibar Solana A, Bois JE, Zaragoza J, Bru N, Paillard T, Generelo E. Adolescent's sedentary behaviors in two European cities. Res Q Exercise Sport. 2015; 86(3): 233 243.

8. Kipping RR, Howe LD, Jago R, Campbell R, Wells S, Chittleborough CR et al. Effect of intervention aimed at increasing physical activity, reducing sedentary behaviour, and increasing fruit and vegetable consumption in children: active for life year 5 (AFLY5) school based cluster randomized controlled trial. BMJ. 2014; 27, $348: \mathrm{g} 3256$.

9. Griew P, Page A, Thomas S, Hillsdon M, Cooper AR. The school effect on children's school time physical activity: the PEACH project. Prev Med. 2010; 51: 282-286.

10. Bringolf-Isler B, Kriemler S, Mäder U, Dössegger A, Hofmann H, Puder JJ,BraunFahrländer C. Relationship between the objectively-assessed neighborhood area and activity behavior in Swiss youth. Prev Med Rep. 2014;1: 14-20.

11. Andersen HB, Klinter CD, Toftager M, Pawlowski CS, Schipperijn J. Objectively measured differences in physical activity in five types of schoolyard area. Landscape Urban Plan. 2015; 134: 83-92.

12. Mota, J, Silva P, Santos MP, Ribeiro JC, Oliveira J, Duarte JA. Physical activity and school recess time: differences between the sexes and the relationship between children's playground physical activity and habitual physical activity. J Sports Sci. $2005 ; 23(3): 269-275$.

13. Ridgers ND, Stratton G, Fairclough, SJ. Assessing physical activity during recess using accelerometry. Prev. Med. 2005; 41(1): 102-107.

14. Guinhouya BC, Lemdani M, Vilhelm C, Hubert H, Apété GK, Durocher A. How school time physical activity is the "big one" for daily activity among schoolchildren: a semi-experimental approach. J Phys Activ Health. 2009; 6(4), 510-9. 
15. Taverno Ross SE, Dowda M, Colabianchi N, Saunders R, Pate RR. After-school setting, physical activity, and sedentary behavior in 5th grade boys and girls. Health Place. 2012; 18(5):951-955.

16. Gao Z, Chen S, Huang CC, Stodden DF, Xiang P. Investigating elementary school children's daily physical activity and sedentary behaviours during weekdays. J Sports Sci. 2016; doi: 10.1080/02640414.2016.1157261

17. Crouter SE, Flynn JI, Bassett DR Jr. Estimating physical activity in youth using a wrist accelerometer. Med Sci Sports Exer. 2015; 47(5): 944-951.

18. Fairclough SJ, Noonan R, Rowlands AV, Van Hees V, Knowles Z, Boddy LM. Wear Compliance and Activity in Children Wearing Wrist- and Hip-Mounted Accelerometers. Med Sci Sports Exer. 2016; 48(2): 245-53.

19. Cole T, Bellizzi MC, Flegal KM, Dietz WH. Establishing a standard definition for child overweight and obesity worldwide: international survey. Brit Med J. 2000; 320 (7244): 1240-1243.

20. Tudor-Locke C, Craig CL, Beets MW, Belton S, Cardon GM, Duncan S et al. ..., Blair SN. How many steps/day are enough? For children and adolescents. Int J Behav Nutr Phy. 2011; 8: 78.

21. Riso EM, Kull M, Mooses K, Hannusand A, Jürimäe J. Objectively measured physical activity levels and sedentary time in 7-9-year-old Estonian schoolchildren:

22. McManus AM, Mellecker RR. Physical activity and obese children. J Sport Health. Sci. 2012; 1: 141-148. attending after-school programs. Med Sci Sports Exer. 2008; 40(4): 622-629. 
24. Pau M, Leban B, Corona F, Gioi S, Nussbaum MA. School-based screening of plantar pressures during level walking with a backpack among overweight and obese schoolchildren. Ergonomics. 2016; 59(5): 697-703.

25. Simmonds M, Burch J, Llewellyn A, Griffiths C, Yang H, Owen C et al. The use of measures of obesity in childhood for predicting obesity and the development of obesity-related diseases in adulthood: a systemic review and meta-analysis. Health Technol Asses. 2015; 19(43): 1-336

26. Drenowatz C, Eisenmann JC, Pfeiffer KA, Welk G, Heelan K, Gentile D et al. Influence of socio-economic status on habitual physical activity and sedentary behavior in 8- to 11-year old children. BMC Public Health. 2010; 10:214.

27. Eime RM, Charity MJ, Harvey JT, Payne WR. Participation in sport and physical activity: associations with socio-economic status and geographical remoteness. $B M C$ Public Health. 2015; 15:434. 
Table 1 Details of the two school schedules available for primary schoolchildren in Italy

\section{School Schedule}

\begin{tabular}{ccc}
\hline & Regular Time (RT) & Full Time (FT) \\
\hline Entry & $8: 25$ AM & $8: 25$ AM \\
Lessons (1st block, RT, FT) & $8: 30$ - 10:30 AM & $8: 30$ - 10:30 AM \\
First Recess (RT, FT) & $10: 30-10: 45$ AM & $10: 30$ - 10:45 AM \\
Lessons (2nd block) & $10: 45-1: 30$ PM & $10: 45-12: 30$ AM \\
Lunch (FT) & - & $12: 30$ - 1:30 PM \\
End of Lessons (RT) & $1: 30$ PM & \\
Second Recess (FT) & - & $1: 30$ - 2:30 PM \\
Lessons (3rd block, FT) & - & $2: 30$ - 4:30 PM \\
End of Lessons (FT) & - & $4: 30$ PM \\
\hline
\end{tabular}


Table 2 Anthropometric and demographic aspects of the participants. Values are expressed as mean $\pm \mathrm{SD}$.

\begin{tabular}{cccc}
\hline & Regular Time & Full Time & p-value \\
\hline Participants \# $(\mathrm{M}, \mathrm{F})$ & $90(42 \mathrm{M}, 48 \mathrm{~F})$ & $79(34 \mathrm{M}, 45 \mathrm{~F})$ & - \\
Age & $8.7 \pm 1.5$ & $8.4 \pm 1.5$ & 0.226 \\
Stature $(\mathrm{cm})$ & $131.7 \pm 11.3$ & $130.3 \pm 11.0$ & 0.428 \\
Body Mass $(\mathrm{kg})$ & $28.7 \pm 7.4$ & $28.6 \pm 8.2$ & 0.883 \\
Body Mass Index $\left(\mathrm{kg} \mathrm{m} \mathrm{m}^{-2}\right)$ & $16.3 \pm 2.2$ & $16.5 \pm 2.4$ & 0.642 \\
Weekly Accelerometer Wear time $(\mathrm{min})$ & $9219 \pm 686$ & $9156 \pm 627$ & 0.153 \\
\hline
\end{tabular}


Table 3 Physical activity patterns for the morning, afternoon and evening time slots during weekdays. Values are expressed as mean \pm SD.

The symbol * denotes statistical significance after Bonferroni correction $(\mathrm{p}<0.0125)$

\section{Physical Activity Patterns}

\begin{tabular}{cccccccccc}
\hline & \multicolumn{3}{c}{ Morning (8:30 AM - 1:30 PM) } & \multicolumn{2}{c}{ Afternoon } & $(1: 30$ PM - 4:30 PM) & \multicolumn{2}{c}{ Evening (4:30 PM - 10:30 PM) } \\
\hline & Regular Time & Full Time & $\begin{array}{c}p \text {-value } \\
\text { schedule }\end{array}$ & Regular Time & Full Time & $\begin{array}{c}p \text {-value } \\
\text { schedule }\end{array}$ & Regular Time & Full Time & $\begin{array}{c}p \text {-value } \\
\text { schedule }\end{array}$ \\
\hline Sedentary (\%) & $65.11 \pm 9.16$ & $64.94 \pm 10.13$ & 0.910 & $60.04 \pm 9.93$ & $54.73 \pm 11.11$ & $<0.001^{*}$ & $65.04 \pm 9.25$ & $63.48 \pm 9.81$ & 0.291 \\
Light (\%) & $23.89 \pm 5.50$ & $25.55 \pm 6.49$ & 0.074 & $24.96 \pm 6.05$ & $27.26 \pm 5.94$ & 0.014 & $19.44 \pm 4.96$ & $20.90 \pm 5.14$ & 0.062 \\
MVPA (\%) & $10.99 \pm 4.72$ & $9.5 \pm 4.64$ & 0.041 & $14.99 \pm 6.12$ & $18.00 \pm 7.68$ & $\mathbf{0 . 0 0 4}$ & $15.52 \pm 5.97$ & $15.61 \pm 6.51$ & 0.926 \\
Steps (\#) & $4358 \pm 933$ & $4237 \pm 894$ & 0.394 & $2971 \pm 699$ & $3242 \pm 728$ & 0.014 & $5188 \pm 1275$ & $5266 \pm 4143$ & 0.705 \\
\hline
\end{tabular}

${ }^{*}$ denotes statistical significance after Bonferroni correction $(p<0.0125)$ 